\title{
EFFECT OF MELATONIN ON THE ULTRASTRUCTURE OF ENTEROCYTES IN RATS AFTER TOTAL BODY IRRADIATION
}

\author{
Abdul Monem Al - Hayani \\ Anatomy Department, Faculty of Medicine and Allied Sciences \\ King Abdul Aziz University, Jedda, Saudia Arabia
}

\section{INTRODUCTION}

The intestinal absorptive cells "enterocytes" represent the most common cell lineages covering the intestinal villi. These cells are considered as the most rapidly renewing tissues of the body and hence, they are very sensitive to the effects of various cytotoxic insults (Burkitt et al., 1993).

In the field of radiotherapy, ionizing radiation is used to damage target cells or tissue. However, the irradiation also damages the non-target cells or tissues (von Sonntag, 1987). The high sensitivity of the gastrointestinal tract to ionizing radiation renders it a possible target in accidentally exposed persons and a dose limiting tissue in some radiotherapy practices. It was also. reperted that the damage to the gastrointestinal tract seems to be of primary concem for the local X-irradiation of abdominal or pelvic tumors, as well as for the whole-hody $\mathrm{X}$-irradiation preceding bone marrow transplantation (Otchy and Nelson, 1993; Allgood et al., 1996).

A large number of clinical reports on radiation enteritis or radiation-induced enteropathy was recorded after the use of different radiation therapy protocols for the treatment of abdominal or pelvic tumors (Olasolo, 1989; Busch, 1990). However, despite of the constant renewal of the irradiation schemes as well as radiation sources and qualities used, the occurrence of radiation enteritis is incr asing due w the increasing number of cancer patients requiring radiotherapy (Allgood et al., 1996). It was reported that ionizing radiation-induced mucosal atrophy is often complicated by ulceration, existence of atypical hyperplastic glands and cystic glandular inclusions, intestinal wall fibrosis, obliterated vascular sclerosis and lymphatic dilatation (Hauer-Jensen, 1990). In clinical terms. the effects of the ionizing radiation on the gut could be grouped into two main categories : prodromal effects that $\alpha c c u r$ 
at relatively low doses of exposure ( $1 \mathrm{~Gy})$ and the gastrointestinal syndrome occurring after higher radiation doses (> $10 \mathrm{~Gy}$ ). As to the time course of events, ionizing radiation effects in the gut have been staged as the initial phase ( 1 - 3 days after exposure) followed by the acute, subacute and late phases of the manifest illness (Anno et al., 1989; Rubio and Jalnas, 1996).

In the mean time, a great deal of work has been done to analyze systematically the histopathology of the irradiation damage of the intestine in human, but the morphologic parameters connected with irradiation remain cumbersorne. In fact, the study of the morphologic changes following irradiation of small intestine of human subjects requires a large number of resected specimens, which was practically difficult to obtain. To bypass that snare, experimental models have been designed (Hauer-Jensen et al., 1988).

The irradiation changes in the small intestine of the experimental animals were confirmed in patients irradiated for abdominal tumors. Many studies reported that 24 - 48 hours after exposure to ionizing irradiation, the villi shortened and the total thickness of muçosa is reduced (Olasolo, 1989; Heimann et al., 1993; Otchy and Nelson, 1993). However, in spite of research efforts in the last two decades to disclose the underlying mechanisms, the overall origin of the aforementioned changes still remained unclear, and needs further study.

Oxidative stress is reported as a complication of bodily irradiation. It has been reported that membrane lipids are susceptible to radiation-induced oxidative stress, and the resulting lipid peroxidation products are the factors causing the radiationinduced toxicity, although it is generally agreed that DNA is the dominant target (Dubner et al., 1995; Umegaki et al., 1999). It has also been shown that the accumulation of lipid peroxidation products is associated with most of the degenerative diseases and aging (Von Sonntag, 1987; Ames and Gold, 1991). Meanwhile, a number of therapeutic planes were directed to evaluate the usefulness of antioxidant administration in order to decrease the tissue damage after exposure to irradiation (Umegaki et al., 1995). Among these strategies is the melatonin (N-acetyl-5methoxytryptamine), a hormone produced by the pineal gland. Melatonin is the most known powerful antioxidants, which stimulates the glutathione peroxidase and can play an essential role in the prevention from oxidative damage (Kaya et al., 1999; Reiter et al., 2003). The protective effect of melatonin was reported after exposure to irradiation (Vijayalaxmi et al., 1995). Many studies also, confirmed this protective effect in rats treated with myelotoxic drugs (Maestroni et al., 1994 - a, b). They reported that melatonin could rescue hematopoiesis from the toxic effect of cancer 
chemotherapeutics. Anwar et al. (1998) also, reported the potential protective effect of melatonin on bone marrow and lymphoid tissues of rats exposed to cytotoxic drugs.

This work was designed in rats to give an insight on the detailed ultrastructural changes of the enterocytes following the effect of total body irradiation and the possible beneficial radioprotective effect of melatonin.

\section{MATERIAL AND METHODS}

Thirty-six adult male Sprague-Dawley rats (weighing $190 \pm 20$ grams) were used in this study. These rats were bred at the animal house of Faculty of Medicine and Allied Sciences of King Abdul Aziz University. They were housed individually in an adjusted temperature of $23 \pm 1^{\circ} \mathrm{C}$ and a $12 \mathrm{~h}$ light-dark cycle with free access to feed and water throughout the experimental period. At the beginning of the experiment (day $O$ ), the rats were randomly divided into four equal groups $(n=g)$ :

\section{- Group I :}

Received no irradiation or melatonin throughout the experimental period (-ve control group).

\section{- Group II :}

Received intraperitoneal (IP) injection of $5 \mathrm{mg} / \mathrm{kg}$ melatonin (Sigma Co.) (+ve control group).

\section{- Group III :}

Received one dose of total body irradiation.

\section{- Group IV :}

Received IP injection of $5 \mathrm{mg} / \mathrm{kg}$ melatonin (Vijayalaxmi et al., 1995) followed after two hours by one dose of total body irradiation.

For total body irradiation, the rats of groups III and IV were anaerthetized wil., $60 \mathrm{mg} / \mathrm{kg}$ ketamin and then fixed to a wood plate with the extremities immobilized with adhesive tape. Irradiation with a single dose of 10 Gray (Gy) to the abdomen over 6 minutes was done using a Toshiba $\mathrm{KXC}-18 \mathrm{X}$-ray generator, operating at 160 KVP and $25 \mathrm{~mA}$ with $0.5 \mathrm{~mm} \mathrm{Al}+0.5 \mathrm{~mm} \mathrm{Cu}$ filter by two anterior-posterior opposing fields of total body. This dose was chosen because it represents the LD 50 
and therefore allows direct comparison with other studies (Alexandrides et al., 1998).

After two days, all the rats were sacrificed by lethal dose of pentobarbital injected intraperitoneally. The intestine was immediately flushed with cold physiologic saline medium then rapidly dissected to separate jejunum and reverted. Small sliccs of jejunum ( $1 \mathrm{~mm}$ in width) were cut and fixed in $2.5 \%$ buffered glutaraldehyde ovemight, then postfixed in $2 \%$ osmium tetraoxide for two hours at $4^{\circ} \mathrm{C}$. The specimens were washed twice in phosphate buffer, dehydrated in ascending grades of ethanol, cleared in three changes of propylenc oxide and finally embedded in Epon 812 at $60^{\circ} \mathrm{C}$ for two days. Sectioning was done using LKB ultramicrotome. Ultrathin seclions ( $400^{\circ} \mathrm{A}$ thick) were double-stained with uranyl acetate and lead citrate, then examined with Philips 300 Electron Microscope, operating at $80 \mathrm{~K}$. V. (Robinson et al., 1987).

\section{RESULTS}

\section{Control rats :}

The ultrastructural examination of the epithelial lining of the small intestine from rats of both groups I and II revealed similar observations, which showed mainly the presence of the absorptive cells "cnterocytes" with some goblet cells. The enterocyte's surface showed enormous number of minute parallel and cylindrical microvilli which were usually of a uniform length. The microvilli showed thick prominent covering of glycocalyx and their cytoplasmic core showed fine filaments, which cxtended basally into the superficial cytoplasm to become integrated into the cytoskeleton of the body of the cell, forming their terminal webs (Figs. 1, 2).

The lateral plasma membranes of enterocytes were seen of tenly interdigitated; they are tightly bound just below their luminal surface by junctional complexes in the form of tight junctions (zonula occludens), adhering junctions (zonula adherens) and scattered desmosomes; basally the enterocytes are separated from each other by intercellular clefts (Figs. 2, 3).

The enterocytes possessed cytoplasm full of different cellular organclles. The cytoplasm appcared to have a granular appearance due the presence of numerous free ribosomes. The mitochondria were particularly abundant and they have typical cylindrical or rod-shaped with organized cristae. Abundant amount of the endoplasmic reticulum. whether smooth or rough, was observed in close awwition with the mitochondria. The Golgi apparatus was usually found n: ar the nucleus and showed 
dilatations of its cisternae and some small vesicles. Also, many lysosomes of variable size and shape were present either in the form of Iry lysosomes which were recognized as membrane-bound organelles containing an amorphous material or 2ry lysosomes which were recognizable by their diverse particulate content some of which is extremely electron dense. In addition, deeper in the cell, some filaments were readily identified. One of the characteristic features of the enterocyte's cytoplasm is the presence of many endocytotic vesicles of diverse size and shape, which were of ten seen as small vesicles between the bases of microvilli in addition to some larger membranous vesicles which were common in the superficial cytoplasm (Figs. 4, 5, $6)$.

The nuclei of the enterocytes were usually oval in shape and basal in position with apparent nucleolus and nuclcoplasm consisting of a finely granular component with a thin peripheral chromatin condensation and narrow perinuclear space (Figs. $6.7)$.

\section{Irradiated rats :}

After irradiation, a series of morphological alterations in the ultrastructure of enterocytes were seen; the type and severity of these changes were different from one rat to another. In general, the microvilli of most of the enterocytes showed marked reduction in number and abnormal configuration in the form of swelling and alteration of the bordering membrane with changes in its length, diameter and number where they became shorter and wider. In most of cases, the microvilli showed rarefaction of their interior due to loss of their filamentous core, with disappearance of their terminal web. This led to loss of the straightness of the microvilli. which displayed bending and beaded-shaped appearance. Moreover, partial loss of the microvilli with discontinuity of the luminal surface of some enterocytes could be seen (Figs. 8, 9, 10).

The opposed surfaces between the enterocytes frequently possessed many lateral projections and irregularity in width with lost continuity in some places. In addition, the junctional complexes between these cells showed abnormal configuration and appeared either loose or thickened (Figs. 8, 9, 10).

Regarding the cytoplasm, a wide rang of changes could be observed. In some enterocyles, the cytoplasm might keep its granular appearance due to the presence of the free rhosomes. which appeared in such situations coarser and aggregated in groups. Huwever in some other enterocytes, disappearance of this free ribosomes with cysic degeneration and rarified areas of the cytoplasm were seen. Moreover. 
disappearance of the endocytic vesicles from the superficial cytoplasm with redistribution or even disappearance of the cytoplasmic filaments has been found. One of the most important changes was the occurrence of many lysosomes (either in the form of 1ry or 2ry lysosomes) of variable sizes and amounts in the superficial portions of the enterocytes. These lysosomes were often aggregated in groups and predominantly found within that part of the cytoplasm that filled with the endoplasmic reticulum. In addition, the cytoplasm might contain heterolysosomes or multivesicular bodies containing phagocytosed debris (Figs. 10, 11, 12).

Another type of pathological change affected the mitochondria, which appeared swollen with variability in size and shape. Also, many mitochondria displayed broken cristae and rarefaction of the matrix. In addition, the rough endoplasmic reticulum showed dilation and loss of the attached ribosomes with focal or concentric arrangement of its channels. The smooth endoplasmic reticulum showed increased number of dilated and swollen cisternae (vesicularization). The Golgi apparatus in some enterocytes either disappeared or appeared distinct in other cells with some of its cisternae markedly dilated and filled with amorphous material (Figs. 10, 11, 12).

The nuclei, showed some changes in the nuclear shape in the form of swelling, loss of rounded or oval appearance, irregularity of the border, dilatation of the nuclear envelope, disappearance of nucleoli and the presence of condensed peripheral chromatin (Fig. 13).

However in addition to the previous findings, some enterocytes displayed more severe changes where complete loss of the microvilli from the luminal surface could be seen. In addition, some enterocytes either lost their luminal surface with release of the cytoplasmic organelles or showed complete breakdown of their junctional complexes and complete separation between the cells (Fig. 14).

\section{Irradiated rats following treatment with melatonin :}

In the irradiated rats previously treated with melatonin, most of the enterocytes took a picture which was more or less near to the normal ultrastructure except for some morphologic alterations. Regarding the microvilli, although they were enormous in number and appeared long, they lost their straightness and had beadedshaped appearance with undistinguished filamentous core and non-prominent covering of glycocalyx. Also, most of the cells displayed a well preserved terminal web and normally apparent junctional complexes; however the opposed surfaces of the cells showed more digitations than usual (Figs. 15, 16). 
Regarding the cytoplasm, it kept its granular appearance due the presence of free ribosomes. The other cytoplasmic organelles displayed a picture more or less near to the normal configuration, except for the golgi apparatus which could not be seen and the presence of dilated smooth endoplasmic reticulum and increased amount of membranous vesicles and lysosomes either primary or secondary. Also, the mitochondria showed diversity in size and shape (Figs. 17, 18, 19). The nuclei of the enterocytes were usually oval in shape and basal in position with some irregularity in outline and condensed peripheral chromatin (Fig. 19). 


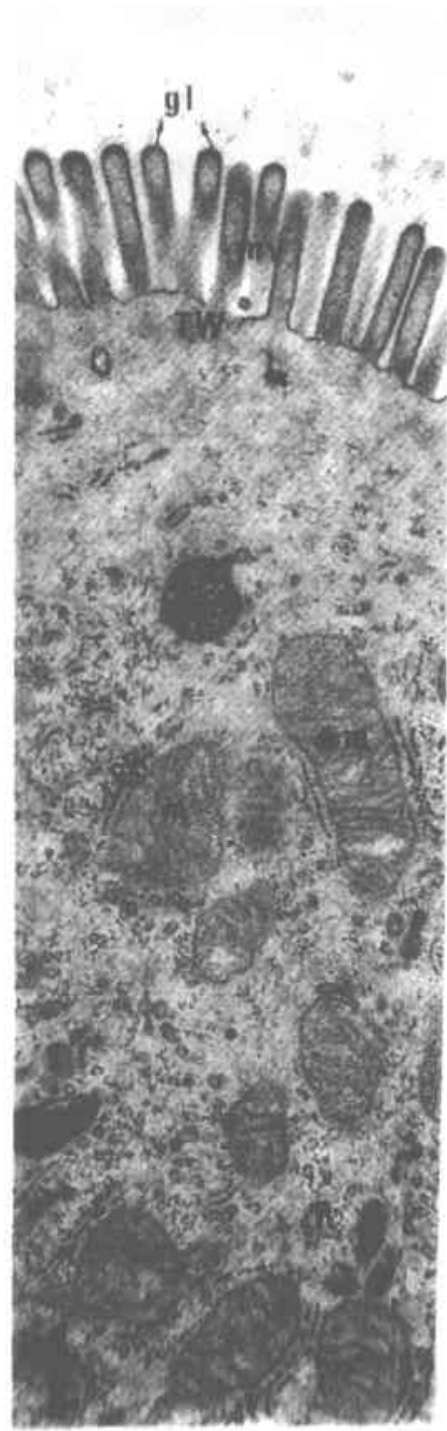

Fig. (1) :Transmission electron photomicrograph of small intestine from a control rat, showing part of the intestinal absorptive cell "enterocyte". The enterócyte's luminal surface showed numerous minute parallel and cylindrical microvilli (mv) which have thick prominent covering of glycocalyx (gl) and their cytoplasmic core showed fine filaments. The later extended basally into the superficial cytoplasm to become integrated into the cytoskeleton of the body of the cell, forming the terminal web (TW). $(m=$ mitochondria, $r E R=$ rough endoplasmic reticulum, $\mathrm{R}=$ free ribosomes). 


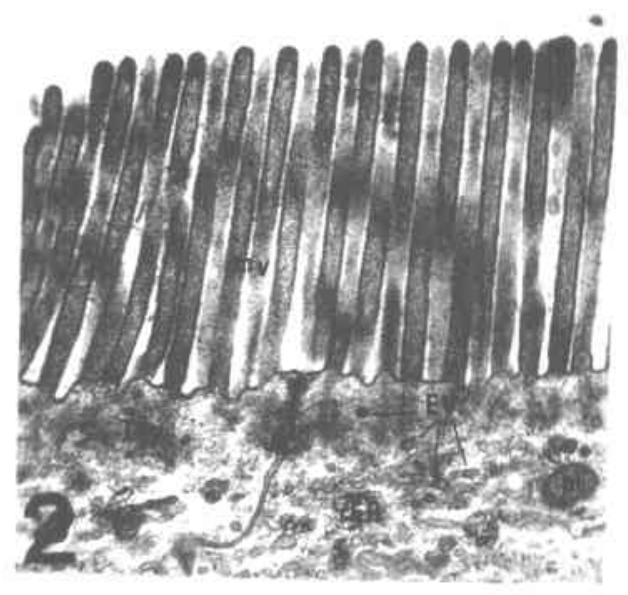

Fig. (2) :Transmission electron photomicrograph of small intestine from a control rat, showing upper parts of two adjacent enterncytes. The luminal surface of the enterocytes showed numerous number of minute, parallel, cylindrical microvilli (mv). The opposed surfaces of the enterocytes are interdigitated: they are tightly bound near their luminal surface by junctional complex (JC). (TW = terminal web, $\mathrm{m}=$ mitochondria, $\mathrm{rER}=$ rough endoplasmic reticulum, $\mathrm{EV}=$ endocytotic vesicles) .

$(\mathrm{x} 10000)$

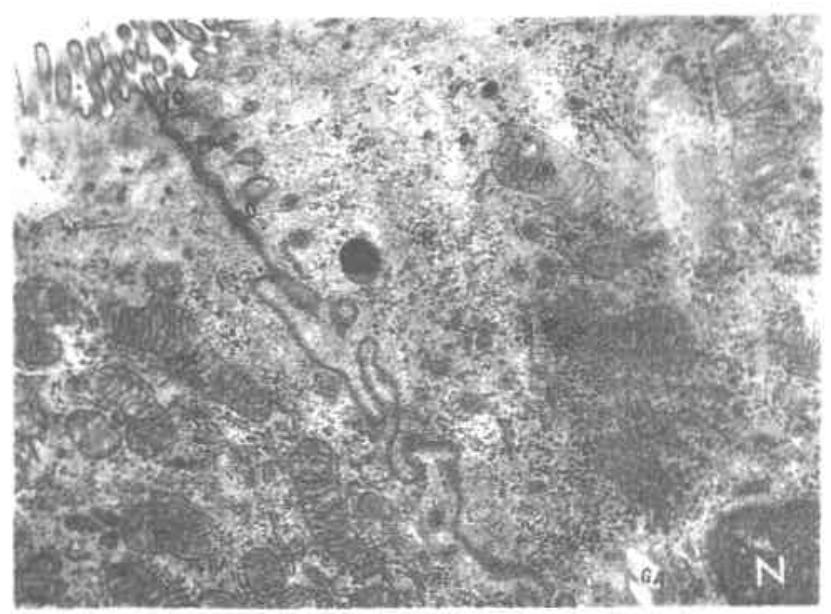

Fig. (3) :Transmission electron photonticrograph of small intestine from a control rat, howing upper parts of two adjacent enterocytes. Notice that the lateral plasma membranes of enterocytes are bound near their luminal surface by junctional complexes in the form of tight junctions (zonula occludens) (ZO), adhering junctions (zonula adherens) (ZA) and scattered desmosomes (D). The Golgi apparatus (GA) was usually localized in the supranuclear and apical regions and showed dilatations of its cistemae and some small vesicles, In addition, deeper in the cell, some filaments (F) were readily identified. ( $m=$ mitochondria, $\mathrm{rER}=$ rough endoplasmic reticulum, $\mathrm{R}=$ free ribosomes, $\mathrm{N}=$ nucleus). 


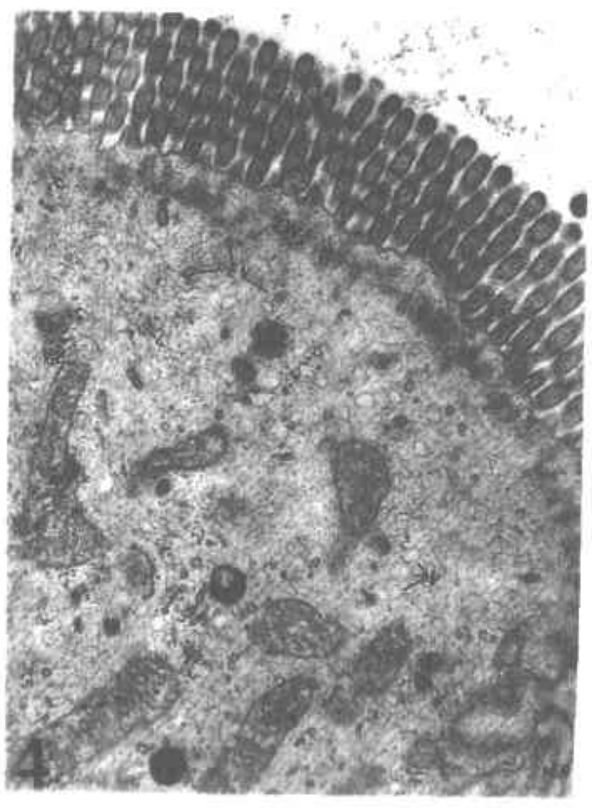

Fig. (4) :Transmission electron photomicrograph of small intestine from a control rat, showing the upper part of the enterocyte. The apical cytoplasm appeared to have many endocytotic vesicles (EV) and some membranous vesicles (V) of diverse size and shape between the bases of microvilli ( $\mathrm{mv}$ ). The mitochondria $(\mathrm{m})$ were abundant and have cy. lindrical or rod-shaped with organized cristae. Rough endoplasmic reticulum(rER) was observed in close association with the mitochondria. Also, many 1 ry lysosomes (Ly 1) and 2 ry lysosomes ( $\mathrm{Ly} 2$ ) of variable size and shape were present. (IW = teminal web).

$(x$ 10000)

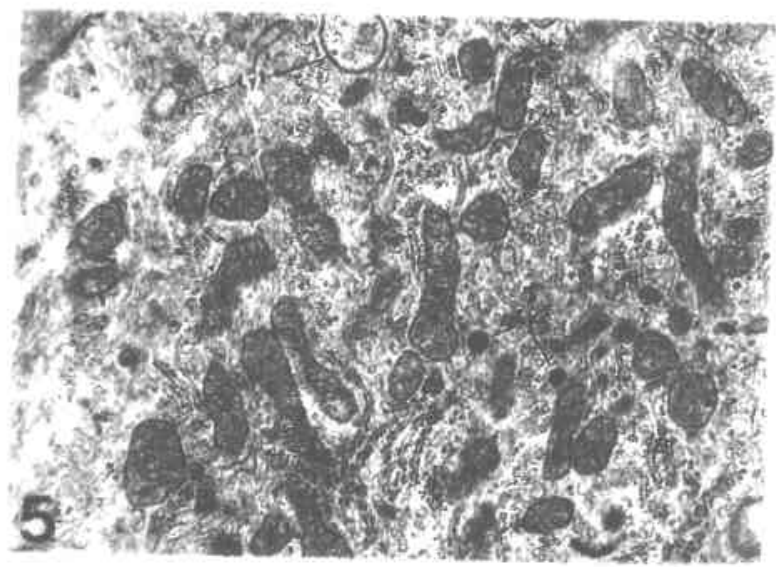

Fig. (5) : Transmission electron photomicrograph of small intestine from a control rat, showing part of the entrocyte. The cytoplasm appeared to have a granular appearance due the presence of numerous free ribosomes (R). The mitochondria (m) were abundant. Rough endoplasmic reticulum ( $\mathrm{rER}$ ) was observed in close association with the mitochondria. Also, few lysosomes of variable size and shape were present either in the form of lry lysosomes (Ly 1) or 2ry lysosomes ( Ly 2).

$(x$ 10000) 


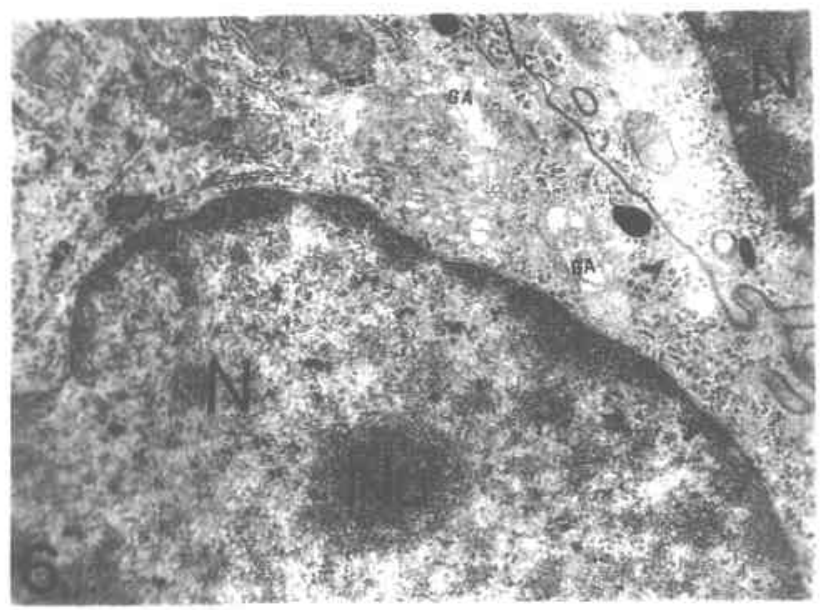

Fig. (6) :Transmission electron photomicrograph of small intestine from a control rat, showing the basal parts of two adjacent enterocytes separated by interdigitated cell membranes (IC). The nuclei (N) of the enterocytes were usually oval in shape and basal in position with apparent nucleolus (Nu) and nucleoplasm consisting of a finely granular component with a thin peripheral chromatin condensation and narrow perinuclear space. The Golgi apparatus (GA) was usually found near the nucleus and showed dilatntions of its cisternae and some small vesicles. $(m=$ mitochondria, $r E R=$ rough endoplasmic reticulum ).

$(\times 8000)$

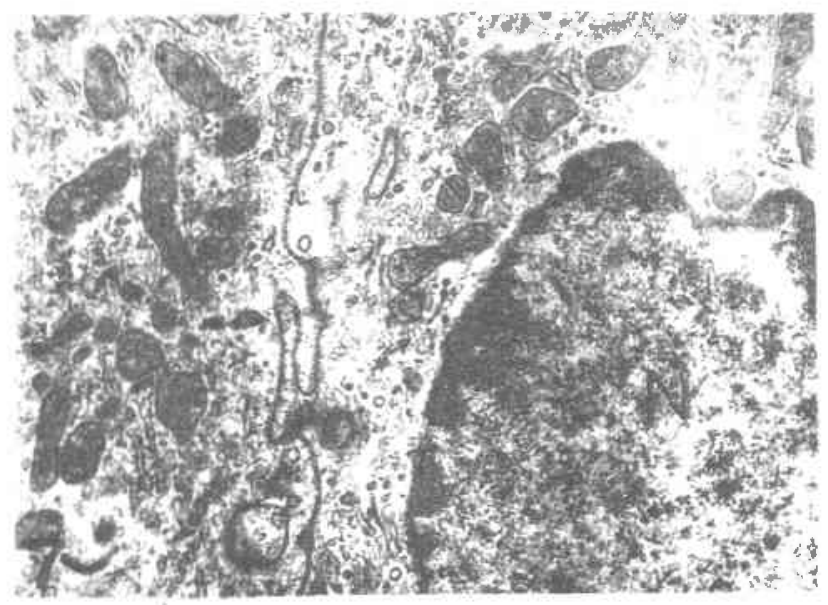

Fg. (7) :Transmission electron photomicrograph of small intestine from a control rat, showing adjacent parts of two enterocytes separated by interdigitated cell membranes (IC). The nucleus (N) of the enterocyte was usually oval in shape and basal in position with nucleoplasm consisting of a finely granular component with a thin peripheral chromatin condensation and narrow perinuclear space. ( $\mathrm{m}=$ mitochondria, $\mathrm{rER}=$ rough endoplasmic reticulum). 


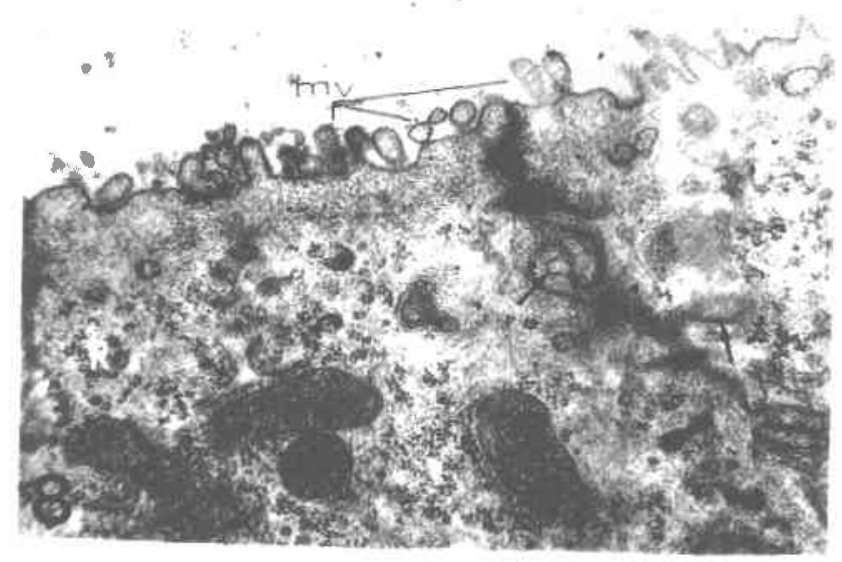

Fig. (8) :Transmission electron photomicrograph of small intestine from an irradiated rat, showing upper parts of two adjacent enterocytes. The luminal surface of the enterocytes showed abnormal-shaped microvilli $(m v)$, which appeared very short, swollen with no glycocalyx and cut from the surface. Notice the absence of the terminal web and the junctional complex between the two cells appeared abnormat with many lateral projections in their opposed surfaces ( $T$ ). The cytoplasm appeared granular due to presence of coarse free ribosomes $(\mathrm{R})$. ( $\mathrm{m}=$ mitochondria, $\mathrm{rER}=$ rough endoplasmic reticulum $)$.

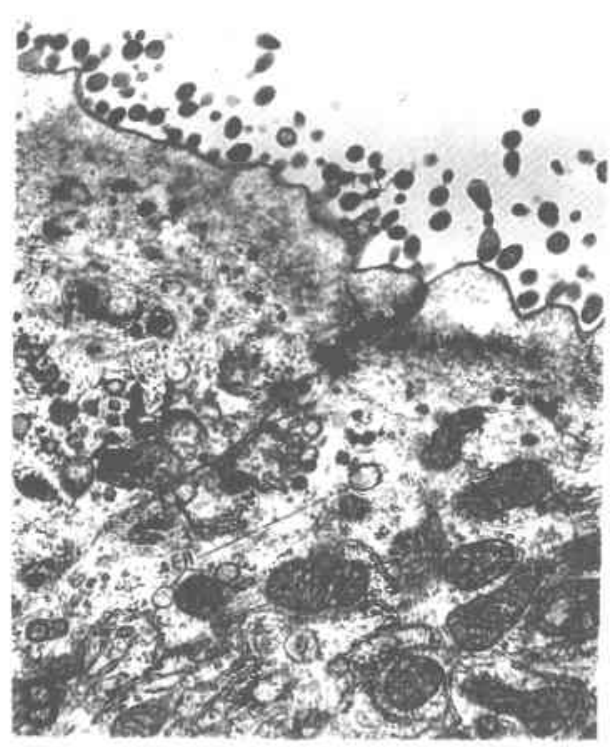

Fig. (9) :Transmission electron photomicrograph of small intestine from an irradiated rat, showing upper parts of two adjacent enterocytes. The luminal surface of the enterocytes showed abnomal-shaped sparse short microvilli ( $m v$ ) and thick abnomal terminal web (TW). Notice that the junctional complex between the two cells appeared abnomal with lost continuity $(\uparrow)$. ( $F=$ filaments, $m=$ mitochondria, rER $=$ rough endoplasmic reticulum, sER = smooth endoplasmic reticulum).

(x 10000) 


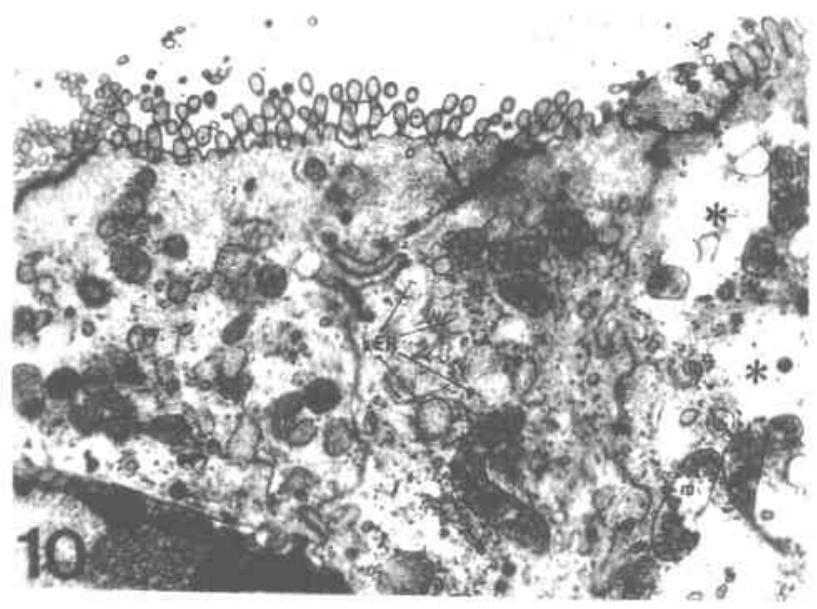

Fig. (10) :Transmission electron photomicrograph of small intestine from an irradiated rat. showing upper parts of many adjacent enterocytes. The luminal surface of the enterocytes showed abnomal-shaped short and sparse microvilli (mv). Notice the absence of the terminal web and that the junctional complex between the cells appeared abnomal $(\neq)$. Also, notice the presence of empty areas of the cytoplasm $(*)$, abnomal shaped mitochondria ( $\mathrm{m})$. dilated smooth endoplasmic reticulum (sER) and some Iry lysosomes (L.y1).

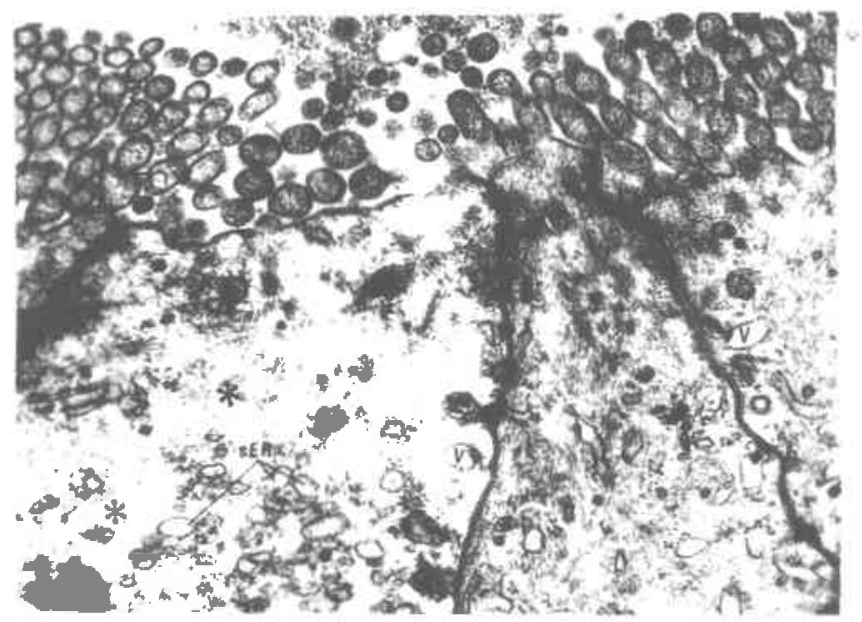

Fig. (11): Transmission electron photomicrograph of small intestine from an irradiated rat, showing upper parts of two adjacent enterocytes. The luminal surface of the enterocytes showed abnomal-shaped short and sparse microvilli (mv). The apical cytoplasm showed marked damage in the fom of complete rarification of the cytoplasm $\left(^{*}\right)$, decreased number of cytoplasmic organelles, presence of many dilated smooth endoplasmic reticulum (sER) and some membranous vesicles (V). 


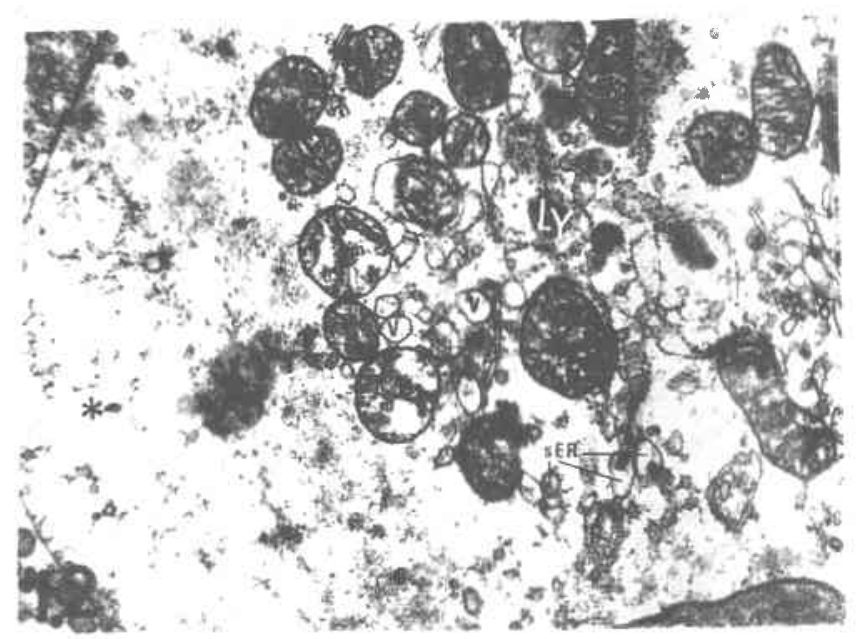

Fig. (12) :Transmission electron photomicrograph of small intestine from an irradiated rat, showing part of an enterocyte. The cytoplasm appeared severely affected showing large areas of rarification (*) with disappearance of the free ribosomes and the rough endoplasmic reticulum. Moreover. little numbers of organelles were displayed in the form of : mitochondria $(m)$ which appeared swollen, variable in size and shape with broken cristae and rarefied matrix, dilated smooth endoplasmic reticulum (sER) which showed vesicular degeneration and many membranous vesicles (V) and lysosomes (Ly).

$(\mathrm{x} 10000)$

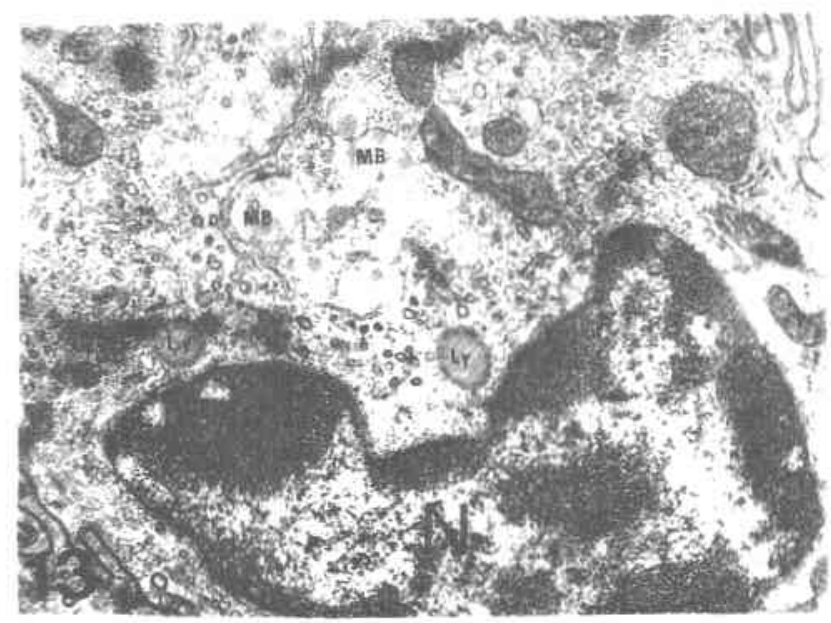

Fig. (13) : Transmission electron photomicrograph of small intestine from an irradiated rat, showing part of the enterocyte. The nucleus (N) showed irregular shape and the presence of condensed peripheral chromatin. The nearby cytoplasm showed many multivesicular bodies (MB), lysosomes (Ly) and abnormal mitochondria $(\mathrm{m})$.

(x 10000) 


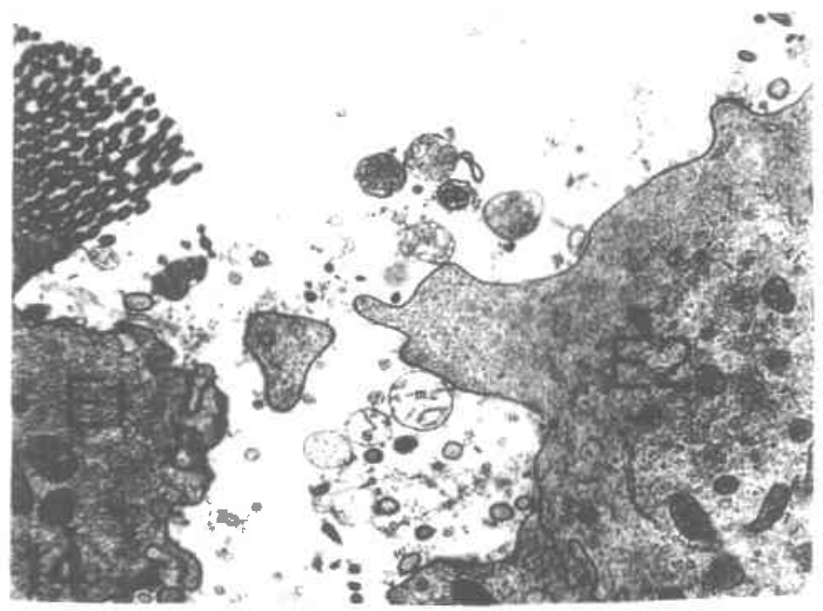

Fig. (14) : Transmission electron photomicrograph of small intestine from an irradiated rat, showing two separated enterocytes due to breakdown of their junctional complex with release of some cytoplasmic organelles. One cell (E 1) showed abnomal beaded-shaped microvilli (mv), while other cell (E 2) showed complete loss of the microvilli. ( $m=$ mitochondria).

(x 6000)

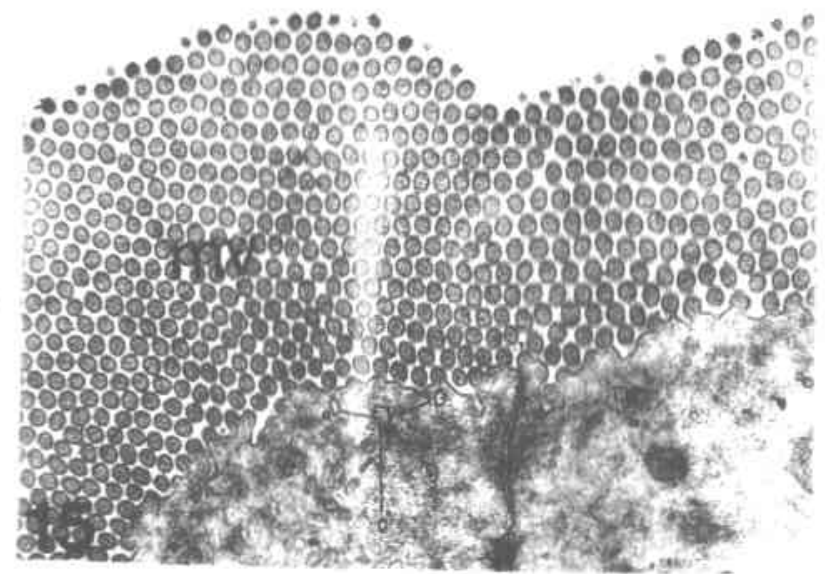

Fig. (15) :Transmission electron photomictograph of small intestine from an irradiated rat trealed with melatonin, showing the upper parts of two adjacent enterocytes. The microvilli ( $m v$ ) although they were enomous in number and appeared long, they lost their straight ness and had beaded-shaped appearance With undistinguished filamentous core and unprominent covering of glycocalyx. Notice that teminal web (TW) was preserved and the junctional complex (JC) was apparently nomal. (EV = endocytotic vesicles).

(x 10000) 


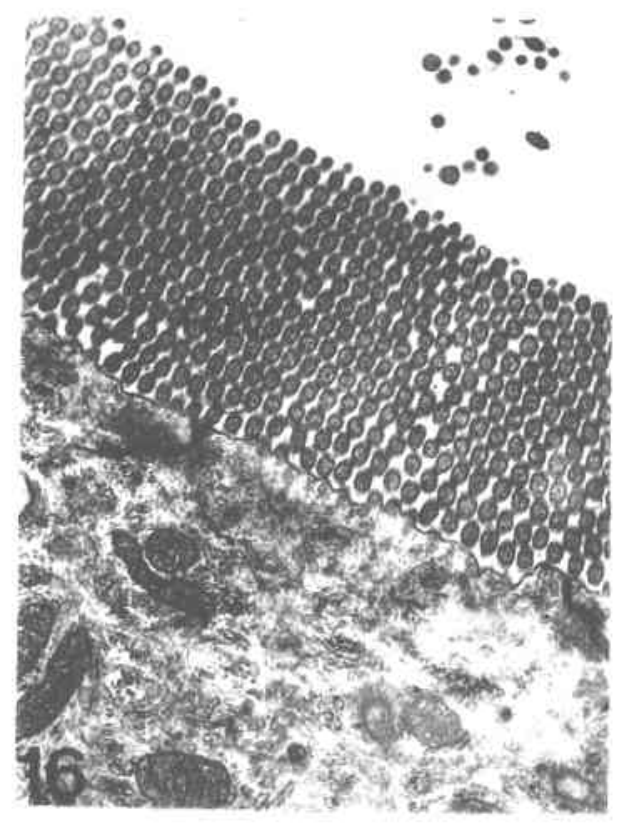

Fig. (16) :Transmission electron photomicrograph of small intestine from an irradiated rat treated with melatonin, showing the upper parts of two adjacent enterocytes. The microvilli (mv) were enomous, long and had beaded-shaped appearance with illdefined terminal web. ( $\mathrm{C}=$ junctional complex, $\mathrm{m}=$ mitochondria).

( 10000$)$

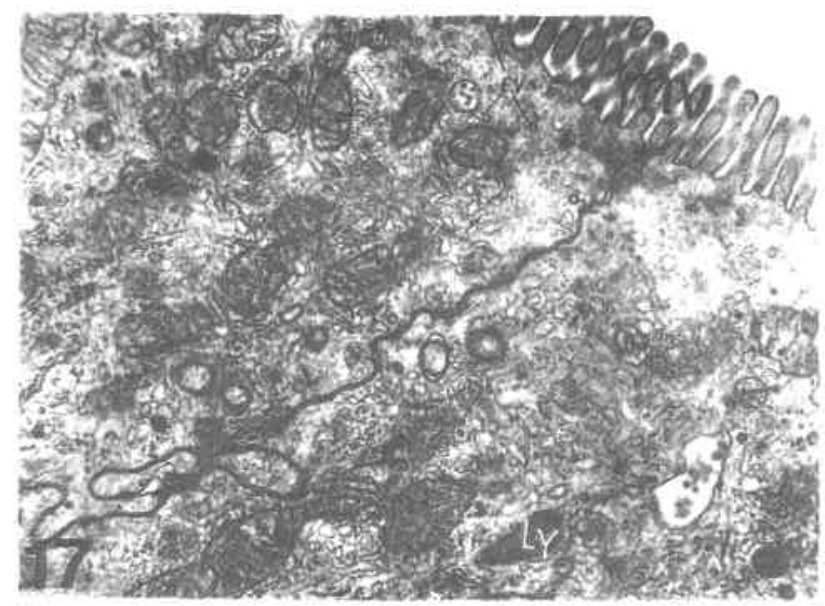

Flg. (17) :Transmission electron photomicrograph of small intestine from an irradiated rat treated with melatonin, showing the opper parts of two adjacent enterocytes with nomally appearing junctional complex (JC). The cytoplasm appeared nomal and contained many mitochondria (m) and endocytotic vesicles $(\mathrm{EV})$. ( $\mathrm{mv}=$ microvilli, $\mathrm{rER}=$ rough endoplasmic reticulum. $\mathrm{I}, \mathrm{v}=$ lysosomes $)$.

$(\mathrm{x}$ 10000) 


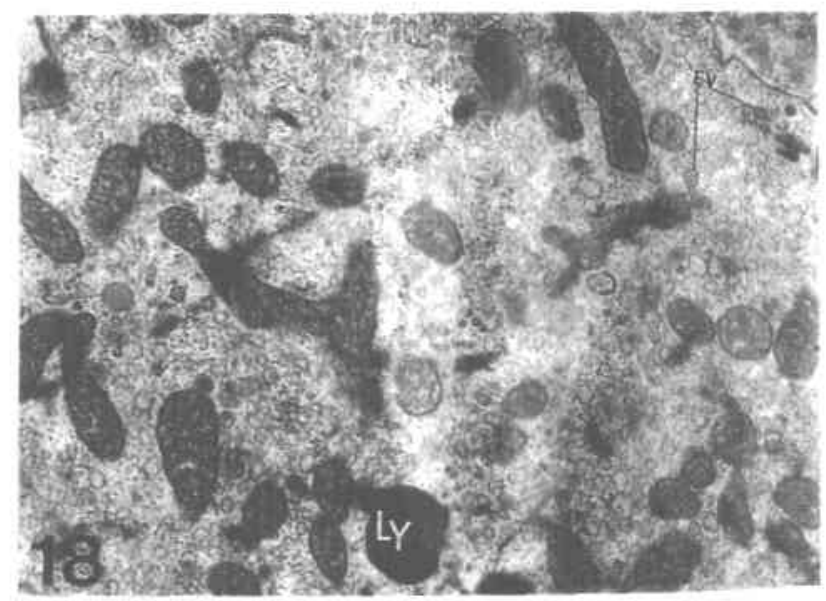

Fig. (18) :Transmission electron photomicrograph of small intestine from an irradiated rat treated with melatonin. showing part of the enterocyte. The cytoplasm appeared nomal and contained many mitochondria (m) of variable size an shape and endocytotic vesicles (EV). (Ly = lysosome).

$(\mathrm{x} 10000)$

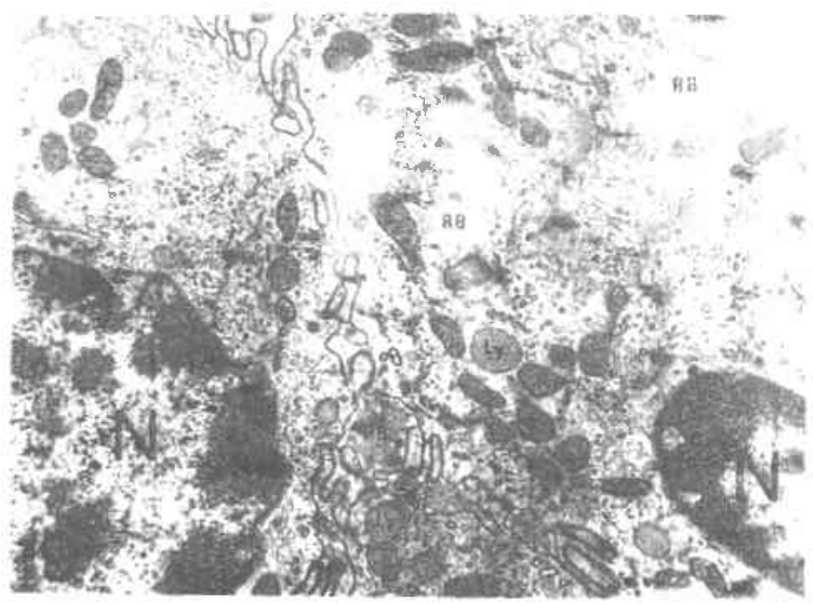

Fig. (19) :Transmission electron photomicrograph of small intestine from an irradiated ral treated with melatonin, showing parts of two adjacint enterocytes with more or less nomally appeared nuclei (N) except for some in the irregularity of the nuclear envelope and condensed chromatin. Notice that the opposed surfaces displayed marked interdigitated bordering and that the cytoplasn contained abnomnal shaped mitochondna (m). lysosomes (Ly) and some nesidual bodies (RB).

$(\mathrm{x} 6000)$ 


\section{DISCUSSION}

The radiation enteritis or radiation-induced enteropathy is a serious short-term side effect of anti-tumoral radiation therapy that generally occurs as a consequence of radiotherapy procedures affecting the abdominal and pelvic regions and occurs in about one-fourth of the treated patients (Anno et al., 1989; Olasolo, 1989). The need to limit the irradiation side effects has brought many investigators to explore the hypothesis that certain trophic factors could be utilized as adjuvant therapy before or during irradiation procedures to achieve this goal (Alexandrides et al., 1998; Boushey et al., 1999; Mylonas et al., 2000; Deng et al., 2002).

Although in the last two decades many studies were published to explain the underlying mechanisms responsible for the irradiation lethality, the overall origin of the aforementioned changes still unclear, and needs further study (Langberg et al., 1994; Potten et al., 1994 a; Dignass et al., 1996; Johnston et al., 1996; Xia et al., 1996). In this concen, this work was prompted to study the detailed ultrastructure study of the enterocytes; the commonest cells of the intestinal epithelium. These cells have many important functional roles. It is generally accepted that after sufficiently high doses of ionizing radiation, death may occur as a direct consequence of damage to the intestinal epithelium (Hauer-Jensen, 1990; Potten et al., 1995; Langberg et al., 1996; Langberg and Hauer-Jensen, 1996). However, this was against what has been thought until recently that the complications of the $X$ irradiated gut depend mainly on the number of surviving stem cells of the intestinal crypts (Potten et al., 1994 b; Potten et al., 1995; Carr et al., 1996).

A significant body of scientific data showed that the clinical symptoms of the radiation enteritis are ruled by the loss of integrity of the intestinal epithelium, which is the earliest responding tissue in this organ, and they are generally complicated by the irreversible damage of the haemopoietic and immune system (Anno et al., 1989; Olasolo, 1989). Also, it was reported that usually severe gastrointestinal tract haemorrhage, endotoxemia and bacterial infection, anorexia, nausea and vomiting, duarrhea and loss of electrolytes and fluids characterize this syndrome. Moreover, it was stated that the irradiation-induced alteration of the fluid and electrolyte balance may be attributed to the direct effects on the cellular transport processes, and to secondary effects like of the radiation-released mediators, the changes of the intestinal blood flow, or loss of the absorptive cells following denudation of the intestianl villt. Bacterial products play an essential rolc in the alteration of cellular communicaltun following irradiation. These processes result in real life threatening condition. 
which, without medical intervention and care, usually lead to death within 2 wekks (Langberg et al., 1994; Potten et al., 1994 a; Dignass et al., 1996; Johnston et al., 1996; Xia et al., 1996).

In the present study, two days after exposure some morphological changes of the intestine of irradiated rats were observed, where the villi shortened in length and the total thickness of the mucosa was reduced. Electron microscopic investigation revealed further alterations in shape and surface of the villus. This is in agreement with many previous studies which showed that different types of ionizing radiationinduced cell loss that led to similar changes within 24 - 48 hours after exposure (Rao and Fritz-Niggli, 1988; Chwals and Bistrian, 1991; Otchy and Nelson, 1993). Other studies reported that the appearance of these morphological changes of the villi depended upon the quality and dose of irradiation, and could be altered by other modalities (Rao and Fritz-Niggli, 1988; Dickson et al., 1992; Carr et al., 1991; 1992; 1996). However, some of studies mentioned that the reported morphological reactions of the intestine were non-specific for irradiation. Similar alterations were described following other treatments or diseases (Rao and Fritz-Niggli, 1988; Dickson et al., 1992).

In this study, the microvilli of most of the enterocytes showed marked reduction and abnormal configuration in the form of swelling and alteration of bordering membrane with changes in length and diameter and loss of glycocalyx. Similar observations were previously reported in many experimental studies which showed that at first the microvilli changed in length, diameter and frequency and then gradually became shorter and wider. Later on, the intestine contained cells with abnormal, sparse, flattened and branched microvilli (Carr et al., 1992; 1996). According to these authors, these micro-villar changes, clearly explained the reduction of surface area and altered transport functions of the irradiated small intestine. Consequently, malabsorption of vitamins, iron, magnesium, calcium and nutrients occurs. Also, it was added that the water and electrolyte transport across the mucosa could be markedly inhibited resulting in loss of fluid leading to dehydration, electrolyte depletion and even death in some cases (Rao and Fritz-Niggli, 1988; Chwals aid Bistrian, 1991; Otchy and Nelson, 1993).

The epithelial cells attach to each other and to teh basal membrane via several types of adherent junctions. Changes in these have long been widely sludicd using both in vivo and in vitro systems. It is well known that tight junctions play an important role in constructing the transport barrier between the basal and luminal side of the epilhelia. Para-cellular transport processes have a great importance in the 
pathology of the different organs, especially of the intestines (Somosy et al., 1995). Therefore studies of irradiation-induced tight junction's changes deserved special attention in radiobiology (Barcellos-Hoff, 1998; Giancotti and Ruoslahti, 1999, Somosy, 2000).

In this study, after exposure to irradiation, the enterocytes frequently showed abnormal junctional complexes or even loosened their contact to each other and possessed many lateral and basal projections. Similar features were reported in some previous experimental studies (Carr et al., 1992; 1996). The later authors stated that the changes of the junctional complexes were responsible for altered interactions between enterocytes and this might ne critical for the maintenance of normal, balanced homeostasis. Experimental evidence showing that disrupting this balance could in. duce aberrant cell proliferation, adhesion, function and migration was reviewed by Barcellos-Hoft (1998).

In the present study, marked changes in the cytoplasmic organelles (mitochondrial swelling, degranulation of the rough endoplasmic reticulum and vesicularization of the smooth endoplasmic reticulum, enlargement of the Golgi complex, redistribution and appearance of many lysosomes and vacuoles and or reorganization of the cytoplasmic filaments) have been found. These results were in agreement to some previous studies on the experimental animals, which reported that the radiation-induced reversible cellular injury was accompanied by morphological alterations in the ultrastructure of the enterocytes (Somosy et al., 1994; 1995). Also, a recent study showed that the ionizing irradiation induces an increase in the number and cytoplasmic volume fraction of lysosome-like vacuoles in the enterocytes with the increased activity of lysosomal hydrolases (Somosy et al., 1996). According to the morphometrical and biochemical observation of this study, expansion of lysosomal compartment was accompanied by increased protein degradation in irradiated cells.

Regarding the radioprotection, the results from previous stidies in experimental radiation enteritis and using trophic factors e.g. growth hormone, insulin-like growth factor and glucagon-like peptide 2, were encouraging although positive results on mucosa histology were obtained by administering high dose of these factors (10 times higher than those utilized in humans). Also, results from a recent study showed that a lower dose of recombinant growth hormone was effective in normalizing growth and mucosa protein content after $5 \mathrm{~Gy}$, but not after $10 \mathrm{~Gy}$ radiation dose (Alexandrides et al., 1998; Boushey et al., 1999; Mylonas et al., 2000) 
In the present study, the administration of melatonin to the rats two hours before the irradiation procedure (group IV) greatly ameliorated the ultrastructural features of the enterocyles when compared with those of the irradiated rats (group III). demonstrating its radioprotective effect. We could not detect any work exploring the irradiation protective effect of melatonin on the enterocytes. Its radioprotective ef fect on blood lymphocytes and spermatogenesis was described. Vijayalaxmi et al. (1995) found that human peripheral blood lymphocytes which were pretreated with melatonin in vitro and then exposed to gamma radiation exhibited a significantly reduced incidence of chromosomal aberrations and micronuclei. as compared with similarly irradiated lymphocytes which werc not pretreated with melatonin. Confirmation of the same genetic test systems in vivo and in vitro has also been reported by Vijayalaxmi et al. (1996) who mentioned that whole body irradiated mice pretrcated with melatonin exhibited a significant and dose-dependent reduction in the observed incidence of micronuclei. They suggest that these data indicated that melatonin has the ability to protect cells of mice from the damaging effect of acute total body irradiation.

Moreover, Badr et al. (1999) reponted that melatonin after irradiation did not protect against induced chromosomal aberrations in spermatogonia. In their opinion melatonin after irradiation provides no radioprotective effect indicating that melatonin should be inside the cell at the time of exposure to irradiation in order to confer protection. Knowing that ionizing radiation causes its harmful effect through generation of free radicals, the melatonin principal mechanism of action for radioprotection, therefore, could be through its ability as a scavenger for free radicals (Reiter et al., 1998).

In explanation to the action of the action of melatonin, Akbulut et al. (1999) reported that this pineal gland hormone seems to have regulatory role in the proliferation of colony forming units for granulocytes and macrophages in rat bone marrow cell cultures.

It could be concluded that melatonin administration prevents damage inflicted to the enterocytes when given prior to exposure to irradiation. Melatonin radioprotection is achieved by its ability as a scavenger for free radicals generated by ionizing irradiation and probably acts as a growth factor. Concomitant melatonin administration during radiotherapy may be highly effective in the prevention of irradiation-related enteropathy. Further studies are required to establish its possible mechanism(s) of radioprotective action of melatonin on cells. 


\section{SUMMARY}

The enterocytes are the dominant cells of the intestinal epithelium and are considered as the most sensitive cells to the cytotoxic insults. The radiation enteritis or radiation-induced enteropathy is a serious short-term side effect of anti-tumoral radiation therapy that generally occurs as a consequence of certain radiotherapy procedures affecting the abdominal and pelvic regions. The need to understand the details of irradiation damage and to limit its side effects has brought the aim of this study. This work is concemed to study the ultrastructural changes of the enterocytes under the effect of total body irradiation and the possible protective effect of melatonin as adjuvant therapy. Thirty-six adult male rats were used. They were divided into four equal groups $(n=9)$ : (I) negative control, (II) positive control, (III) rats irradiated with a single dose of $10 \mathrm{~Gy}$ and (IV) rats received IP (intraperitoneal) injection of 5 $\mathrm{mg} / \mathrm{kg}$ of melatonin two hours before irradiation with a single dose of $10 \mathrm{~Gy}$. After two days, all the rats were sacrificed and pieces of small intestine were processed to the transmission electronic microscopic examination. The results showed that the enterocytes of the irradiated rats exhibited marked degenerative ultrastructural changes in their microvilli, junctional complexes and cytoplasmic organelles, while in the rats treated with melatonin before irradiation the enterocytes showed much less changes. It could be concluded that prior administration of melatonin seems to prevent radiation damage of the enterocytes.

\section{REFERENCES}

1. Akbulut, H.; Icli, E.; Buyukcelik, A.; Akbulut, K.G. and Demirci, S. (1999) : The role of granulocyte-macrophage-colony stimulating factor, cortisol, and melatonin in the regulation of the circadian rhythms of peripheral blood cells in healthy volunteers and patients with breast cancer. J. Pineal. Res., 26 (1) : 1 - 8.

2. Alexandrides, T.; Spiliotis, J. and Mylonas, P. (1998) : Effects of growth hormone and insulin-like growth factor-l on radiation enteritis, a comparative study. Eur. Surg. Res., 30 : 305 - 311.

3. Allgood, J.W.; Langberg, C.W.; Sung, C.C. and Hauer-Jensen, M. (1996) : Timing of concomitant boost irradiation affects incidence and severity of intestinal complications. International Journal of Radiation-Oncology-Biology-Physics, 34 : 381 - 387. 
4. Ames, B.N. and Gold, L.S. (1991) : Endogenous mutagens and the causes of aging and cancer. Mutat. Res., $250: 3$ - 16.

5. Anno, G.H.; Baum, S.J.; Withers, H.R. and Young, R.W. (1989) : Symptomatology of acute radiation effects in humans after exposure to doses of $0.5-30 \mathrm{~Gy}$. Health Physics, $56: 821-838$.

6. Anwar, M.M.; Mahfouz, H.A. and Sayed, A.S. (1998) : Potential protective effects of melatonin on bone martow of rats exposed to cytotoxic drugs. Comp. Biochem. Physiol. A Mol. Integr. Physiol., 119 (2) : 493 - 501.

7. Badr, F.M.; El Habit, O.H. and Harraz, M.M. (1999) : Radioprotective effect of melatonin assessed by measuring chromosomal damage in mitotic and meiotic cells. Mutat. Res., 444 (2) : 367 - 372 ,

8. Barcellos-Hoff, M.H. (1998) : How does tissue respond to damage al the cellular level ? The role of cytokines in irradiated tissues. Rad. Res., 150 : S 109 - \$ 120.

9. Boushey, R.P.; Yusta, B. and Drucker, D.J. (1999) : Glucagon-like peptide 2 decreases mortality and reduces the severity of indomcthacin-induced murine enteritis. Am. J. Physiol., 277 : E 937 - E 947.

10. Burkitt, H.G.; Young, B. and Heath, J.W. (1993) : Wheater's Functional Histology : a text and colour atlas. Longman Group Ltd., Churchill Livingstone, Ch. $14: 247-270$.

11. Busch, D.B. (1990) : Pathology of the radiation-damaged bowel. In Galland, R.B.; Spencer, J. (Eds.). Radiation Enteritis. Edward Amold. London, 66 - 87.

12. Carr, K.E.; Hume, S.P.; Nelson, A.C.; O'Shea, O.; Hazzard, R.A. and McCullough, J.S. (1996) : Morphological profiles of neutron and X-irradiated small intestine. J. Radiat. Res., $37: 38$ - 48.

13. Carr, K.E.; McCullough, J.S.; Nelson, A.C.; Hume, S.P.; Nunn, S. and Kamel, H.M. (1992) : Relationship between villous shape and mural structure in neutron irradiated small intesine. Scanning Microscopy, 6:561 - 572 .

14. Carr, K.E.; McCullough, J.S.; Nunn, S.; Hume, S.P. and Nelson, A.C. (1991) : Neutron and $X$-ray effects on small intestine summarized by using a mathematical model or paradigm. Proceedings of the Royal Society of London. Series B : Biological Sciences, 243 : 187 - 194.

15. Chwals, W.J. and Bistrian, B.R. (1991) : Role of exogenous growth hormone and insulin-like growth factor 1 in malnutrition and acute metabolic stress : a hypothesis. Critical Care Med., 19 : 1317 - 1322. 
16. Deng, W.; Balazs, L.; Wang, D.A.; Van Middleworth, L.; Tigyi, G. and Johnson, L.R. (2002) : Lysophosphatidic acid protects and rescues intestinal epithelial cells from radiation-and chemotherapy-induced apoptosis. Gastroenterology, $123(1): 206-216$.

17. Dickson, G.B.; Kamel, H.M.K.; Hume, S.P.; Jaber, M. and Carr, K.E. (1992) : Early effects of mouse small intestine of single or combined modality treatment with hypenhennia and X-irradiation. Scanning Microscopy, $6: 847$ 854.

18. Dignass, A.U.; Stow, J.L. and Babyatsky, M.W. (1996) : Acute epithelial injury in the rat small intestine in vivo is associated with expanded expression of transforming growth factor alpha and beta. Gut, $38 ; 687-693$.

19. Dubner, D.; Gisone, P.; Jaitovich, I. and Perez, m. (1995) : Free radicals proirradiation. Biol. Trace Elem. Res., $47: 265$ - 270.

20. Giancotti, F.G. and Ruosiahtl, E. (1999) : Integrin signaling. Science, 285 : $1028-1032$.

21. Hauer-Jensen, M. (1990) : Late radiation injury of the small intestine. Clinical, pathophysiologic and radiobiologic aspects. Acta Oncologica, $29: 401+415$.

22. Hauer-Jensen, M.; Poulakos, L. and Osborne, J.W. (1988) : Effects of accelerated fractionation on radiation injury of the small intestine : A new rat modcl. Int. J. Radiat. Oncol, Biol. Phys., 14:1205 - 1212.

23. Heimann, A.; Gentile, J.; Madariaga, J.; Brand, D.L.; Meek, A.G. and Lane, B. (1993) : Cytologic and histologic changes in irradiated loops of transplanted small bowel. Acta Cytol, $37: 287$ - 299.

24. Johnston, C.J.; Piedboeuf, B.; Rubin, P.; Williams, J.P.; Baggs, R. and Finkel-stein, J.N. (1996) : Early and persistent alteration in the expression of interleukin- 1 alspha, inlerleukin- 1 beta and tumor necrosis factor alpha mRNA levels in fibrosis-resistant and sensitive mice after thoracic irradiation. Radiat. Res., $154: 762-767$.

25. Kaya, H.; Delibas, N.; Serteser, M.; Ulukaya, E. and Ozkaya, O. (1999) : The effect of melatonin on lipid peroxidation during radiotherapy in female rats. Strahlenther Onkol., 175 (6) : 285 - 288.

26. Langberg, C.W. and Hauer-Jensen, M. (1996) : Influence of fraction size on the development of late radiation enteropalhy. An experimental study in the rat. Acta Oncol., $35: 89$ - 94. 
27. Langberg, C.W.; Hauer-Jensen, M.; Sung, C.C. and Kane, C.J. (1994) : Expression of fibrogenic cytokines in rat small intestine after fractionated irradiation. Radioth. And Oncol., 32: 29 - 36.

28. Langberg, C.W.; Sauer, T.; Reitan, J.B. and Hauer-Jensen, M. (1996) : Relationship between intestinal fibrosis and histopathologic and mOT phometric changes in consequential and late radiation erueropathy. Acta Oncol., $35: 81$. 87.

29. Maestronu, G.J.; Covacci, A. and Conti, A. (1994 - a) : Hematopoietic rescue via T-cell-dependent, endogenous granulocyte-macrophage colony-stimulating factor induced by the pineal neurohormone melatonin in tumor-bearing mice. Cancer Res., 54 (9) : 2429 - 2432.

30. Maestroni, G.J.; Conti, A. and Lissoni, P. (1994 - b) : Colony-stimulating activity and hematopoietic rescue from cancer chemotherapy compounds are induced by melatonin via endogenous interlukin 4. Cancer Res., 54 (17) : 4740 4743.

31. Mylonas, P.G.; Matsouka, P.T.; Papandoniou, E.V.; Vagianos, C.; Kalfarentzos, F. and Alexandrides, T.K. (2000) : Growth hormone and insulin-like growth factor 1 protect intestinal cells from radiation induced apoptosis. Mol. Cell Endocrinol., $160: 115-122$.

32. Olasolo, J.J. (1989) : Severe small bowel radiation enteritis. Acta Oncol., 28 : $717 \cdot 720$.

33. Otchy, D.P. and Nelson, H. (1993) : Radiation injuries of the colon and rectum. Surgical Clinics of North America, 73 : 1017 - 1035.

34. Potten, C.S.; Booth, C.; Chadwick, C.A. and Evans, G.S. (1994 a) : A potent stimulator of small intestinal cell proliferation extracted by simple diffusion from intact irradiated intestine $:$ in vitro studies. Growth Factors, $10: 53$ - 61 .

35. Potten, C.S.; Owen, G.; Hewitt, D.; Chadwick, C.A.; Hendry, J.H.; Lord, B.I. and Woolford, L.B. (1995) : Stimulation and inhibition of proliferation in the small intestinal crypts of the mouse after in vivo administration of growth factors. Gut, 36 : 864 - 873.

36. Rao, K.R. and Fritz-Niggli, H. (1988) : Alterations in the length of jejunal villi in mice irradiated with graded doses of X rays. Brit. J. Radio., $61: 839$ - 842.

37. Reiter, R.J.; Guerrero, J.M.; Garcia, J.J. and Acuna-Castroviejo (1998) : Reactive oxygen intermediates, molecular damage, and aging. Relation to melatonin. Ann Y Acad Sci., 854 : 410 - 424. 
38. Reiter, R.J.; Tan; D.X.; Mayo, J.C. Sainz, R.M.; Leon, J. and Czarnocki, Z. (2003) : Melatoninas an antioxidant : biochemical mechanisms and pathophysiological implications in humans. Acta Biochim Pol., 50 (4) : 1129 - 1146.

39. Robinson, D.G.; Uhlers, V.; Herken, R.; Herrmann, B.; Mayer, F. and Schurmann, F.W.. (1987) : Methods of preparation for electron microscope. Springer-Verlag. Berlin, New York, 23 - 66, 148 - 164.

40. Rubio, C.A. and Jalnas, M. (1996) : Dose-time-dependent histological changes following irradiation of the small intestine of rats. Digestive Diseases and Sciences, 41 : 392 - 401.

41. Somosy, Z. (2000) : Radiation response of cell organdies. Micron, $31: 165$ 181.

42. Somosy, Z.; Sass, M.; Bognar, G.; Kovacs, J. and Koteles, G.J. (1995) : Xirra-diation-induced disorganization of cytoskeletal filaments and cell contacts in HT-29 cells. Scan. Microsc., 9 : 763 - 772.

43. Somosy, Z.; Takats, A.; Bognar, G.; Kovacs, A.L.; Telbisz, A.; Racz, A.; Kovacs, J. and Koteles, G.J. (1996) : X-irradiation-induced changes of the prelysosomal and lysosomal compartments and proteolysis in HT-29 cells. Scan. Microsc., $10: 1079$ - 1091.

44. Somosy, Z.; Thuroczy, G.; Koteles, G.J. and Kovacs, J. (1994) : Effects of modulated microwave and $\mathrm{X}$-ray irradiation on the activity and distribution of $\mathrm{Ca}^{2+}$ ATPase in small intestine epithelial cells. Scan. Microsc., $8: 631-620$.

45. Umegaki, K.; Aoki, S. and Esashi, T. (1995) : Whole body X-ray irradiation to mice decreases ascorbic acid concentration in bone marrow : comparison between ascorbic acid and vitamin E. Free Radio. Biol. Med., 7 : 69 - 76.

46. Umegaki, K.; Sano, M.; Suzuki, K.; Tomita, I. and Esashi, T. (1999) : Increase in 4 - hydroxynonenal and hexanal in bone marrow of rats subjected to total body X-ray irradiation : association with antioxidant vitamin. Bone Marrow Transplantation, 23 : 173 - 178.

47. Vijayalaxmi, Reiter, R.J.; Herman, T.S. and Meltz, M.L. (1996) : Melatonin and radioprotection from genetic damage $:$ in vivo / in vitro studies with human volunteers. Mutat. Res., 371 (3 - 4) : 221 - 228.

48. Vijayalaxmi, Reiter, R.J.; Sewerynek, E.; Poeggeler, B.; Leal, B.Z. and Meltz, M.L. (1995) : Marked reduction of radiation-induced micronuclei in human blood lymphocytes pretreated with melatonin. Radiat. Res., 143 (1) : 102 106. 
49. von Sonntag, C. (1987): The Chemical Basis of Radiation Bulogy Tavlor Francis, London, 97 - 108.

50. Xia, Y.; Fertel, R.H. and Wood, J.D. (1996) : Simuatun i) tr)malum :4 adenosine $3^{\prime}, 5^{\prime}$ - phosphate by histamine in myenteric ganglia wolated from gumea pig small intestine. European J. of Pannacology. 316 . $\mathrm{XI}-85$

$$
\text { الملخص العريس }
$$

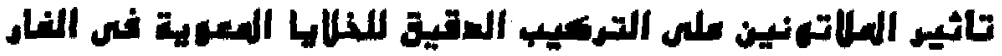

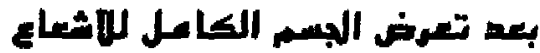

$$
\begin{aligned}
& \text { عبs الهنعم الهيانس } \\
& \text { تسم التشريع - كلية الطب - مالعلىم الطبية }
\end{aligned}
$$

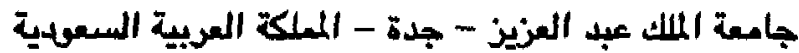

تعتبر الخلايا المعوية هلى السائدة في الخلايا الطلائية للامعاء من أكثر الخلايا

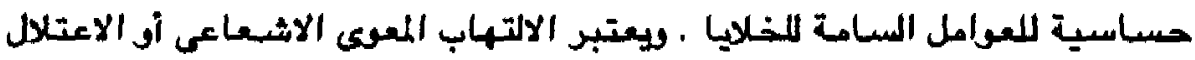

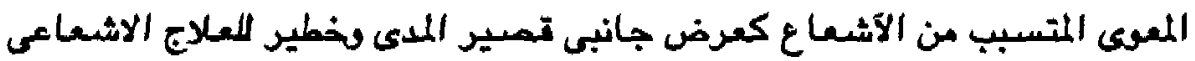

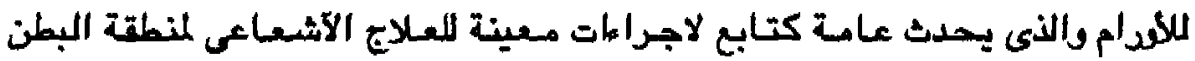
والهضض .

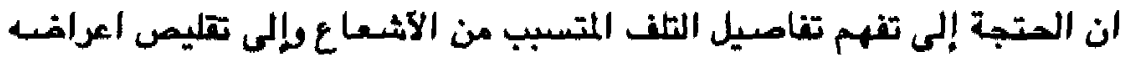
الجتبية كانت وداء الهدف من مذه الدراسة ، ويختص هذا العمل بدراسة التغيرات

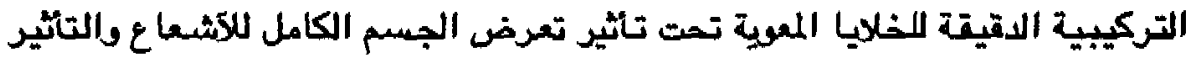

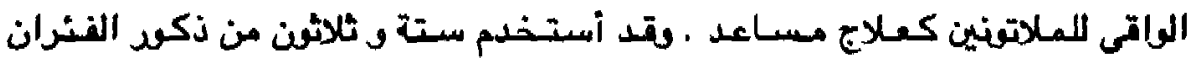
البالغة حيث تسعـوا إلى اربعة مجمرعات متسارية تمترى كل منها على تسعة فنران :

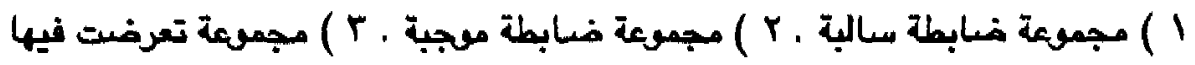

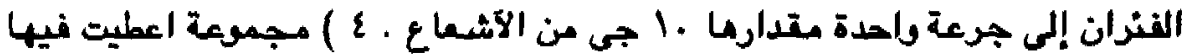




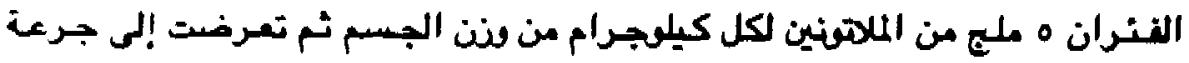

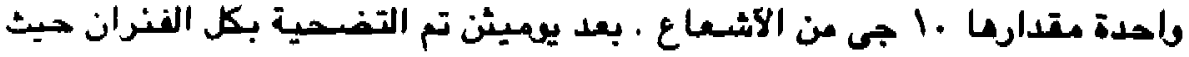

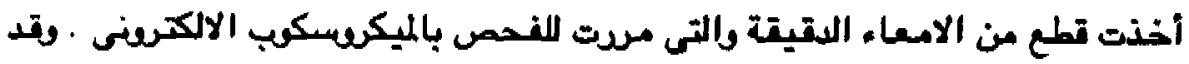

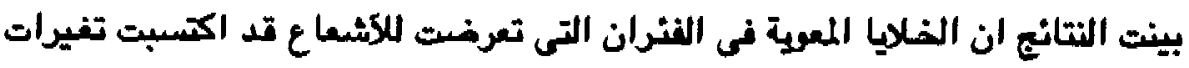

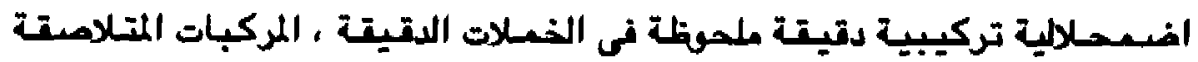

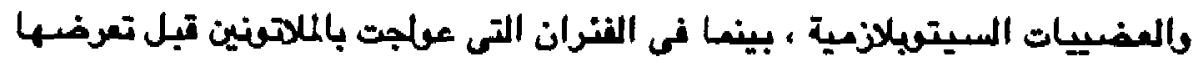

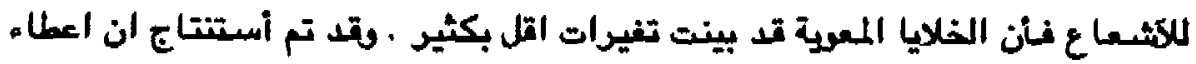

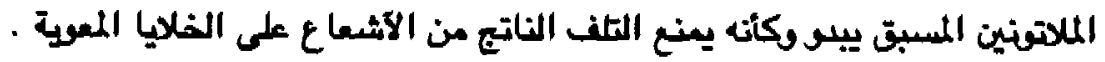

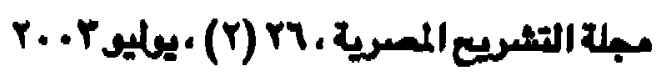

